\title{
REVIEW
}

\section{Angiogenesis in epithelian ovarian cancer}

\section{E S Bamberger, C W Perrett}

J Clin Pathol: Mol Pathol 2002;55:348-359

Angiogenesis, the development of new blood vessels from the existing vasculature, is an essential component of solid tumour growth and metastasis. Several angiogenic factors are expressed by many tumours, suggesting that tumours promote their own vascularisation by activating the host endothelium. This review will discuss various angiogenic stimulators and inhibitors in epithelian ovarian cancer (EOC), including vascular endothelial growth factor and platelet derived endothelial cell growth factor/thymidine phosphorylase. The analysis of tumour vascularisation by microvessel density will also be discussed and the relevance of these markers of angiogenesis in the prognosis of EOC will be assessed.

See end of article for authors' affiliations

Correspondence to Dr C W Perrett Department of 'Obstetrics and Gynaecology, Royal Free and University College Medical School, Royal Free Campus, Rowland Hill Street, London NW3 2PF, UK; c.perrett@rfc.ucl.ac.uk

Accepted for publication 12 July 2002
E pithelian ovarian cancer (EOC) is the most common malignancy of the female genital women develop EOC at some time during their lives. This disease begins in, and is usually limited to, the peritoneal cavity. Most women with EOC present with peritoneal spread, the principal cause of morbidity and mortality. EOC is associated with malignant ascites formation; in most cases, the first indication of EOC is swelling of the abdomen as a result of the accumulation of ascitic fluid. ${ }^{1}$ Owing to the paucity of symptoms and their insidious onset, most patients present with advanced disease, and five year survival rates are approximately $20 \%{ }^{2}$ At present, EOC has by far the worst prognosis of all gynaecological cancers and is responsible for half the deaths caused by female genital tract malignancy. ${ }^{3}$ The ovaries give rise to a wider variety of tumours than any other organ in the body. ${ }^{45}$ The main histological types of EOC are serous and mucinous tumours, with endometrioid and clear cell carcinomas being in the minority. ${ }^{6}$ Tumour type, stage, and grade ${ }^{7}$ have a bearing on the treatment and prognosis of EOC. Staging describes the extent of tumour spread and, of all the prognostic factors, probably has the greatest effect on treatment and prognosis. For EOC, the most commonly used system for staging is that of the International Federation of Gynaecology and Obstetrics (FIGO) $)^{8}$ : stage I, growth limited to the ovaries ( $78 \%$ five year survival); stage II, growth limited to the pelvis (59\% five year survival); stage III, growth extending to abdominal cavity (23\% five year survival); stage IV, metastases to distant sites ( $14 \%$ five year survival). In terms of histological grading, which reflects both architectural and nuclear abnormalities in the tumours, EOC is generally graded according to the following criteria': grade I, well tract in Western countries: $1-2 \%$ of all differentiated tumours; grade II, moderately differentiated tumours; grade III, poorly differentiated tumours.

"At present, epithelian ovarian cancer has by far the worst prognosis of all gynaecological cancers and is responsible for half the deaths caused by female genital tract malignancy"

\section{ANGIOGENESIS AND TUMORIGENESIS}

Embryonic development, reproductive functions (including ovarian cycling), wound healing, rheumatoid arthritis, retinopathies, psoriasis, and tumorigenesis are all proliferative processes that are crucially dependent on the development of a new vascular supply. Angiogenesis is the stimulation of growth of new vascular endothelial cells and the development of new blood vessels. ${ }^{10-15}$ Without angiogenesis tumour expansion cannot proceed beyond 1-2 mm because tumour proliferation is severely limited by nutrient supply to, and waste removal from, the tumour into the surrounding medium. ${ }^{11}$ Therefore, angiogenesis is a crucial factor in the progression of solid tumours and metastases, ${ }^{10-12}$ 15-17 including EOC. ${ }^{18}$ The formation of the vascular stroma plays an important role in the pathophysiology of malignancy. ${ }^{19}$ In the absence of vascular support tumours may become necrotic, or even apoptotic. ${ }^{20}{ }^{21}$ The onset of angiogenesis marks a phase of rapid proliferation, local invasion, and ultimately metastasis, although angiogenesis can also have a role to play in premalignant lesions (for example, those of the cervix and vulva ${ }^{22}{ }^{23}$ ). Vascularisation is a prerequisite for tumour cells to spread by shedding into the circulation; the newly formed, immature, and leaky capillaries aid the process of metastasis because their basement membranes are fenestrated, allowing greater accessibility for stray tumour cells. ${ }^{16}$

\section{ANGIOGENIC FACTORS}

In recent years, much progress has been made in the identification of regulators of angiogenesis.

Abbreviations: Ang, angiopoietin; AVD, average vessel density; bFGF, basic fibroblast growth factor; DFS, disease free survival; ELISA, enzyme linked immunosorbent assay; EOC, epithelian ovarian cancer; FIGO, International Federation of Gynaecology and Obstetrics; HVD, high vessel density; IP mice, mice bearing intraperitoneal tumours; MVD, microvessel density; OHSS, ovarian hyperstimulation syndrome; PD-ECGF, platelet derived endothelial cell growth factor; PIGF, placental growth factor; $\alpha$-SMA, $\alpha$ smooth muscle antigen; TGF transforming growth factor; TP, thymidine phosphorylase; VEGF, vascular endothelial growth factor; VEGFR, vascular endothelial growth factor receptor; VPF, vascular permeability factor; vWF, von Willebrand factor 
Most notably, vascular endothelial growth factor (VEGF) is widely distributed and has been shown to play a coordinated role in endothelial cell proliferation and assembly of the vessel wall in a variety of normal and abnormal circumstances. ${ }^{24-26}$ There are now five members of the VEGF family, in addition to four members of the angiopoietin family and at least one member of the ephrin family of regulators ${ }^{26}$; they must all work in a complementary and coordinated manner to form functional vessels. ${ }^{27}$ In addition, many other growth factors that are not vascular endothelium specific are also required for blood vessel formation, such as members of the platelet derived growth factor and transforming growth factor (TGF) families; these factors also have crucial roles in many other systems. ${ }^{26} 28$

\section{Angiogenic stimulators VEGF}

Several naturally occurring growth factors and cytokines can induce and/or promote angiogenesis by stimulating endothelial cell growth and migration. One of the more potent endothelial mitogens is VEGF, also known as vascular permeability factor, $\mathrm{VPF}^{29}$ because it was initially recognised for its ability to increase microvascular permeability.

VEGF/VPF (now termed VEGF-A) was first identified in 1993 by Senger and colleagues ${ }^{30}$ in the culture supernatant and ascites of rodent tumours. Later, VEGF was found in the malignant effusions of human ovarian, breast, and lung tumours. ${ }^{31}$ By virtue of its permeability inducing properties a central role for VEGF/VPF in tumour stroma generation has been suggested..$^{32}$ In addition, VEGF can act as a specific mitogen for a variety of endothelial cells in vitro and as an angiogenic molecule in vivo. ${ }^{29}{ }^{34-37}$ VEGF is a potent and very specific mitogen for vascular endothelial cells. ${ }^{35-42}$ It stimulates the full cascade of events required for angiogenesis both in vitro and in vivo, ${ }^{42}{ }^{43}$ and greatly augments the permeability of the existing microvasculature. ${ }^{29}{ }^{30}$ It is a potent multifunctional cytokine that exerts several potentially independent actions on the vascular endothelium, ${ }^{29}$ including endothelial mitogenesis, permeability, vascular tone, the production of vasoactive molecules, and the stimulation of monocyte chemotaxis. ${ }^{44}{ }^{45}$ VEGF also functions as a potent prosurvival (antiapoptotic) factor for endothelial cells in newly formed vessels, ${ }^{46-48}$ and this may be one of its most important functions.

\section{"Several studies have now shown that vascular endothelial growth factor is overexpressed in a variety of tumours including those of the breast, ovary, bladder, vulva, uterus, and cervix"}

The human VEGF gene has been mapped to chromosome 6p21.3. ${ }^{49}$ Biochemically, VEGF is a heparin binding glycoprotein that occurs in at least four molecular isoforms; these consist of 121, 165, 189, and 204/206 amino acids and are the result of alternative VEGF mRNA splicing. ${ }^{43}{ }^{44}$ These isoforms have distinct functional properties in terms of heparin binding and diffusibility. VEGF $\mathrm{VEF}_{165}$ is the most common; it binds to heparin and can either be secreted or bind to the cell surface and extracellular matrix. $\mathrm{VEGF}_{121}$ is freely soluble and does not bind to heparin. VEGF 189 is sequestered into the extracellular matrix and may be released by heparin or heparinase.

Several studies have now shown that VEGF is overexpressed in a variety of tumours including those of the breast, ovary, bladder, vulva, uterus, and cervix.22 $29{ }^{30} 50-56$ VEGF values are often raised, and blocking its activity-for example, by specific neutralising antibodies to VEGF or to VEGF receptors (VEGFR) expressed by "activated" endothelial cells-can inhibit experimental tumour growth in vivo, but not in vitro. $^{36} 57$ Thus, tumour cells can "feed" (induce) new blood vessels by producing VEGF which, in turn, can nourish the tumour cells, an insidious and self perpetuating paracrine loop. The possibility of therapeutic disruption of this loop has stimulated an intense search in the biotechnological and pharmaceutical industries, in addition to academic centres, for agents such as anti-VEGF antibodies, ${ }^{58-60}$ VEGF-toxin conjugates, ${ }^{61}$ aptamers, ${ }^{58}$ and small molecule VEGFR antagonists. ${ }^{62} 63$

\section{The VEGF family}

Recent observations have identified a group of several growth factors, the VEGF family, which interact with different receptors to induce endothelial mitogenesis. The most important member of the group is VEGF itself (VEGF-A). In addition to VEGF, the family currently includes: VEGF-B, VEGF-C, VEGF-D, VEGF-E, and placental growth factors PlGF-1 and PlGF-2. ${ }^{26}{ }^{64}$

Mice lacking VEGF-B are overtly normal and fertile, but their hearts are reduced in size, suggesting that VEGF-B may have a role in coronary vascularisation and growth. ${ }^{65}$ VEGF-C, based on its ability to bind the lymphatic specific receptor VEGFR-3 (see below), is important for lymphatic development, and transgenic overexpression of VEGF-C leads to lymphatic hyperplasia. ${ }^{66}$ Little is known about the physiological role of VEGF-D. ${ }^{26}$ Until recently, little was known about the normal function of PlGF, in part because mice genetically engineered to lack this growth factor were overtly normal, ${ }^{26} 67$ However, recent findings indicate that adult mice lacking PlGF exhibit deficiencies in certain models of adult vascular remodelling, raising the interesting possibility that the activity of PlGF may be limited to these settings. ${ }^{26}$

The various members of the VEGF family have overlapping abilities to interact with a set of cell surface receptors ${ }^{68}$ that trigger responses to these factors. These receptors are involved in initiating signal transduction cascades in response to the VEGF and PlGF proteins. They comprise a family of closely related receptor tyrosine kinases consisting of three members now termed VEGFR-1 (previously known as Flt-1), VEGFR-2 (previously known as KDR or Flk-1), and VEGFR-3 (previously known as Flt-3). In addition, there are several accessory receptors, such as the neuropilins, ${ }^{69}$ which seem to be involved primarily in modulating binding to the main receptors, although roles in signalling for these have not been ruled out. VEGFR-2 mediates the major growth and permeability actions of VEGF, whereas VEGFR-1 may have a negative role, either by acting as a decoy receptor or by suppressing signalling through VEGFR-2. Thus, gene knockout mice lacking VEGFR-2 fail to develop a vasculature and have very few endothelial cells, ${ }^{70}$ whereas mice lacking VEGFR-1 have an excess formation of endothelial cells, which abnormally coalesce into disorganised tubules. ${ }^{57}$ Mice genetically engineered to express only a truncated form of VEGFR-1, lacking its kinase domain, appear normal, consistent with the notion that the primary role of VEGFR-1 may be that of a decoy receptor. ${ }^{71}$ VEGFR-3 may be important for blood vessel development, but is unique among the VEGF receptors in that it is also expressed on lymphatic vessels, and may therefore have an important role in lymphangiogenesis. ${ }^{72}$

\section{Platelet derived endothelial cell growth factor/thymidine phosphorylase}

Another factor that has been shown to stimulate angiogenesis is platelet derived endothelial cell growth factor (PD-ECGF). Originally isolated from platelets, this $45 \mathrm{kDa}$ protein promotes cell growth and chemotaxis in endothelial cells in vivo and angiogenesis in vitro. ${ }^{73}$ It has been found in various tissues such as the placenta, lung, endometrium, and ovary, ${ }^{74}$ in addition to certain cancer tissues. ${ }^{75}$ The enzyme thymidine phosphorylase (TP), which catalyses the reversible phosphorylation of thymidine to thymidine deoxyribose $\mathrm{l}^{\prime}$-phosphate, has been shown to be homologous to PD-ECGF. ${ }^{76}$ The byproduct of this reaction, 2'-deoxy-D-ribose, has angiogenic activity. ${ }^{77}$ 
Angiopoietin 1 and angiopoietin 2

Angiopoietin 1 (Ang-1) and Ang-2 are growth factors that are ligands for the "ties", a family of receptor tyrosine kinases that are selectively expressed within the vascular endothelium, as are the VEGF receptors. ${ }^{78-82}$ Although both Ang-1 and Ang-2 bind tie-2, Ang-1 functions as an agonist whereas Ang-2 behaves as an antagonist at this receptor. ${ }^{83}$ Indeed, Ang-2 can cause the regression of newly formed vessels by stimulating endothelial cell apoptosis, unless VEGF is present, in which case the two collaborate to promote angiogenesis. ${ }^{84}$ The ligand for the structurally related receptor, tie-1, remains unknown.

\section{The ephrin family}

Numerous ephrin ligands (for example, ephrin $\mathrm{Al}, \mathrm{Bl}$, and B2) bind to the Eph receptor tyrosine kinases; these comprise the largest known family of growth factor receptors and include EphA2, EphB2, EphB3, and EphB4 $4{ }^{26}$ Recent knockout studies have suggested key roles for ephrin B2 and its EphB4 receptor during vascular development. Mouse embryos lacking ephrin B2 and EphB4 suffer fatal defects in early angiogenic remodelling that are somewhat reminiscent of those seen in mice lacking Ang-1 or tie-2. In adult settings of angiogenesis, as in tumours or in the female reproductive system, the endothelium of new vessels strongly re-expresses ephrin B2, suggesting that ephrin B2 may be important in these angiogenic settings. ${ }^{26}$ The various members of this family appear to regulate the interactions between arterial and venous endothelial cells, as reviewed by other authors. ${ }^{26} 85$

\section{Tissue selective angiogenic stimulators}

Recently, the identification of an angiogenic mitogen selective for one endothelial cell type (the endocrine gland endothelium) has been reported. ${ }^{86}$ The expression of this factor is largely restricted to steroidogenic glands, such as ovary, testis, adrenal cortex, and placenta. Although this protein shows no structural homology with the VEGF family, it displays several striking biological similarities to VEGF: it induces endothelial proliferation and migration, it has the ability to induce fenestration in capillary endothelial cells derived from endocrine glands, and it is regulated by hypoxia. On the basis of such functional homologies, it has been designated endocrine gland derived VEGF. ${ }^{86}$

\section{Angiogenic inhibitors}

A large, growing, and structurally diverse family of endogenous protein inhibitors of angiogenesis has now been discovered, and the potential use of some of these molecules in the treatment of cancer has been evaluated. ${ }^{15}$ They include: thrombospondin $1,{ }^{8788}$ interferon $\alpha / \beta{ }^{89-91}$ the $16 \mathrm{kDa}$ fragment of prolactin, ${ }^{92}$ angiostatin, ${ }^{93}$ endostatin, ${ }^{94}$ vascular endothelial cell growth inhibitor, ${ }^{95}$ vasostatin,, ${ }^{96}$ Meth-1 and Meth-2,, ${ }^{97}$ and cleavage products of platelet factor $4^{98}$ and anti-thrombin III. ${ }^{99}$ Some of these are internal fragments of various proteins that normally lack antiangiogenic activity ${ }^{100}{ }^{101}$-for example, angiostatin is one or more fragment(s) of plasminogen ${ }^{93}$ and endostatin is a fragment of type XVIII collagen. ${ }^{94}$ Many of the precursor proteins are components of the extracellular matrix/basement membrane (for example, type XVIII collagen and thrombospondin) or members of the clotting fibrinolytic pathways (for example, plasminogen and anti-thrombin III). ${ }^{99}$

\section{THE PROCESS OF ANGIOGENESIS}

The process of angiogenesis in adult neovascularisation, including tumour formation, is currently understood as follows $^{26} 84102$ : angiogenesis is primarily mediated by VEGF, which drives endothelial cell proliferation, migration, and tube formation. Subsequently, Ang-1, in physiological situations, leads to vessel maturation and stabilisation. However, such stabilised vessels can be destabilised by Ang- 2 and, in the presence of VEGF, a new round of angiogenesis can begin; in the absence of VEGF, vessel regression would ensue. The balance of at least two biological systems (VEGF-VEGFR and Ang-tie) along with the natural angiogenic inhibitors regulate the outcomes of vessel formation and vessel regression, and these complexities must be taken into account when designing and developing antiangiogenic agents. ${ }^{102}$

\section{MICROVESSEL DENSITY}

The degree of angiogenesis of a tumour, as assessed by microvessel density (MVD), has emerged as a powerful candidate for prognosis and as a predictive tool. ${ }^{103}$ In a multivariate analysis, MVD was found to be the most accurate prognostic indicator in breast carcinoma for disease free survival (DFS); better than size, grade, or oestrogen receptor status. ${ }^{104}$ In other studies, VEGF expression has been demonstrated in a variety of tumours and has been correlated with increased MVD and poor prognosis. ${ }^{105-107}$

"The degree of angiogenesis of a tumour, as assessed by microvessel density, has emerged as a powerful candidate for prognosis and as a predictive tool"

Many studies have used measurements of MVD in regions of high vessel density (HVD), also termed vascular "hotspots", to assess the influence of tumour angiogenesis on prognosis. Early studies ${ }^{108-113}$ showed a prognostic value of MVD in breast cancer and cutaneous melanoma. Further studies have shown a link between MVD and prognosis in several solid tumours, such as those of the breast, lung, prostate, ovary, head and neck, cervix, oesophagus, colon, and non-small cell lung carcinomas. ${ }^{105}{ }^{114-129}$ Kato et al confirmed the prognostic usefulness of tumour MVD in 377 Japanese patients with breast cancer, followed for a median of 10 years. ${ }^{130}$ A raised MVD was associated with both low relapse free and overall survival. Later Gehani et al specifically look at the association between tumour MVD and the subsequent development of bone metastasis in 200 patients with primary breast cancer followed for a minimum of five years. ${ }^{131}$ In multivariate analyses, only MVD and lymph node status remained significantly associated with bone metastasis.

\section{Markers of blood vessels}

A variety of endothelial cell markers have been used to highlight tumour blood vessels immunohistochemically. The most commonly used antibodies include those against factor VIII related antigen, CD31/PECAM-1, and CD34. Factor VIII related antigen forms part of the von Willebrand factor (vWF) complex and plays a role in the coagulation process. ${ }^{132}$ The platelet-endothelial cell adhesion molecule CD31/PECAM-1, is a transmembrane glycoprotein involved in cell adhesion, ${ }^{133}$ and CD34 is a surface glycoprotein of unknown function. ${ }^{134}$ The relative abilities of these antibodies to highlight the vasculature has been examined in several tumours, ${ }^{135} 136$ including EOC (SJ Amis et al, unpublished data, 2002). ${ }^{137} 138$

Detection of blood vessels in tissue sections has recently been modified so that it is now possible to discriminate between newly formed immature vessels and those that are more established and mature. It is based on the use of antibodies to $\alpha$ smooth muscle actin ( $\alpha$-SMA), which appear to stain mature vessels because they attract a "coat" of periendothelial support cells - that is, pericytes and smooth muscle ( $\alpha$-SMA positive) cells. ${ }^{48}$ In this regard, it is of interest to note that antiangiogenic therapeutic procedures, such as the blockade of tumour cell VEGF production, result not only in a drop in the vessel count, but also a change in the ratio of immature/mature vessels because of the relative vulnerability of the immature vessels to this, and most other, forms of antiangiogenic treatment. 

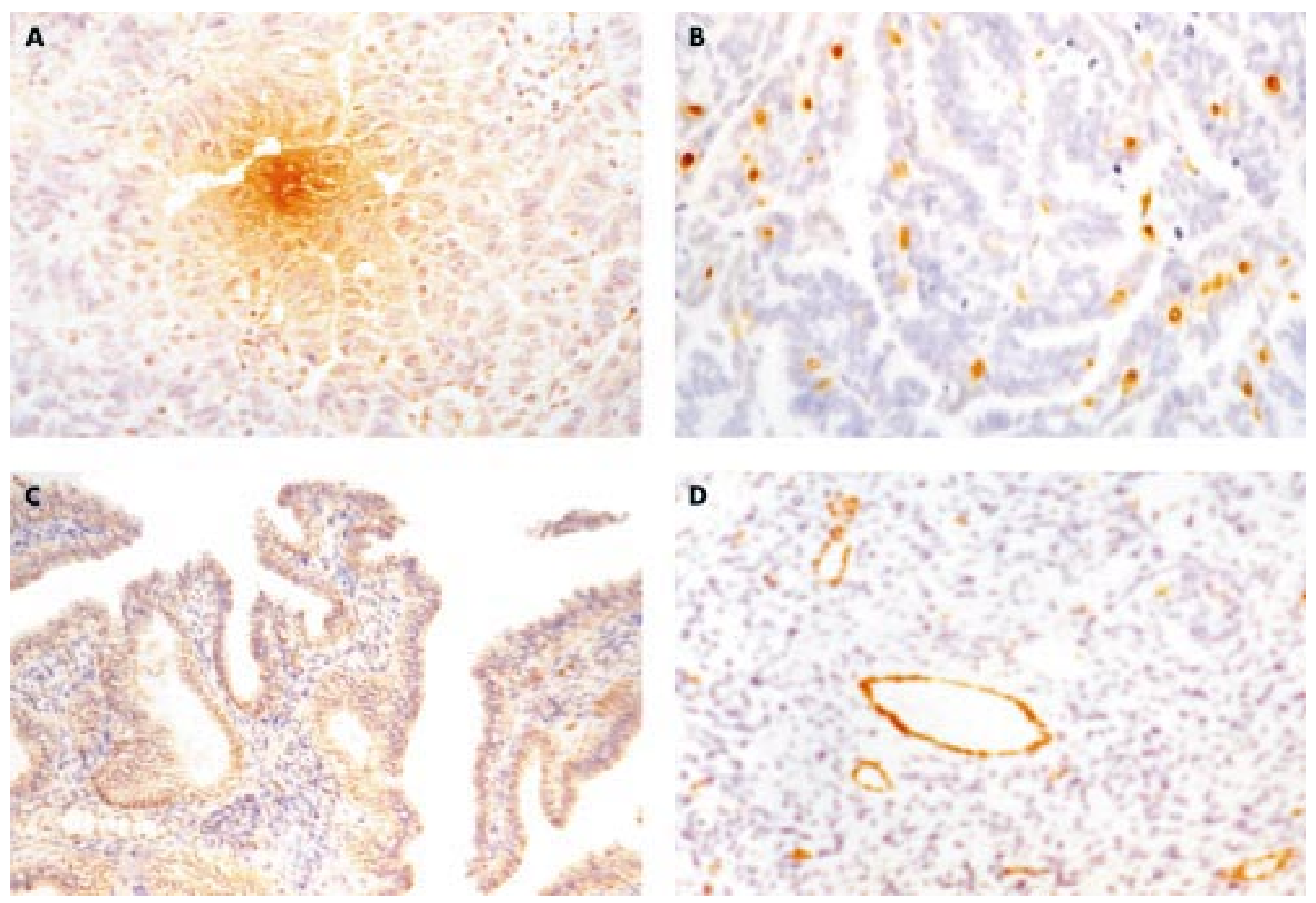

Figure 1 (A) Vascular endothelial growth factor (VEGF) expression in primary serous epithelian ovarian cancer (EOC); original magnification, $\times 100$. (B) Platelet derived endothelial cell growth factor/thymidine phosphorylase expression in primary serous EOC; original magnification, $\times 100$. (C) VEGF-C expression in primary mucinous EOC; original magnification, $\times 16$. (D) van Willebrand factor expression in primary mucinous EOC, showing several microvessels around a blood vessel; original magnification, $\times 100$.

\section{ANGIOGENESIS IN EOC}

\section{VEGF in ovarian tissue and omental metastases}

Several studies have indicated that VEGF regulated angiogenesis is an important component of EOC growth. VEGF immunostaining has been demonstrated in the epithelial lining of benign ovarian neoplasms. ${ }^{139}$ MVD and the degree of expression of VEGF and its receptors in ovarian tumours $^{79} 117$ 140-142 $^{142}$ are directly correlated with poor prognosis, suggesting that angiogenesis, possibly mediated at least in part by VEGF, influences disease progression. ${ }^{140-143}$ In a murine model of EOC, the drug FRI18487, which inhibits angiogenesis by inhibiting basic fibroblast growth factor (bFGF) and VEGF activities, ${ }^{144}$ suppressed the in vivo growth and metastasis of a murine ovarian cancer cell line. ${ }^{145}{ }^{146}$

Olson et al were the first to demonstrate the constitutive gene expression of VEGF in normal and neoplastic human ovaries. $^{51}$ They concluded that VEGF may be an important mediator of the ascites formation and tumour metastasis observed in neoplastic conditions of the ovary.

Using human ovarian tissue, Abu-Jawdeh and colleagues ${ }^{117}$ examined, by in situ hybridisation and immunohistochemical analysis, the expression of VEGF and its receptors in different ovarian tumour types (fig 1A). They reported that VEGF mRNA and protein were expressed by the neoplastic cells in all the malignant tumours evaluated, with most tumours showing strong expression of mRNA. Serous borderline tumours had variable VEGF mRNA expression. No definite expression of VEGF was seen in mucinous borderline tumours. No strong expression of VEGF mRNA was seen in normal ovarian cortex, including surface epithelium, and benign tumours. In addition, microvascular endothelial cells strongly expressed VEGF-R1 and VEGF-R2 mRNA and stained positively for VEGF protein in most of the malignant and borderline tumours examined. These findings suggested that VEGF plays an important role in the angiogenesis associated with ovarian neoplasms.

"The consistent message in these various studies is the potential importance of angiogenesis, as a prognostic tool, during transformation and acquisition of the invasive phenotype of advanced epithelian ovarian cancer"

Wong Te Fong and colleagues ${ }^{147148}$ assessed VEGF in a selection of normal ovaries $(n=10)$, benign cystadenomas $(\mathrm{n}=30)$, primary ovarian tumours including serous adenocarcinomas $(\mathrm{n}=17)$, mucinous $(\mathrm{n}=6)$, endometrioid $(\mathrm{n}=7)$, and clear cell $(\mathrm{n}=2)$. Immunohistochemically, $75 \%$ of the malignant tumours expressed VEGF compared with $13 \%$ in benign cystadenomas and $0 \%$ in borderline tumours and normal ovaries. There was a significant difference in VEGF expression between the histological subtypes: serous subtypes of benign and malignant tumours expressed higher amounts of VEGF proteins; serous adenocarcinomas had significantly higher VEGF expression compared with endometrioid carcinomas. An examination of the relation between VEGF expression and stage of the tumour in this study showed that late stage EOC had strong VEGF expression when compared with early stage EOC. In addition, VEGF-C was highly expressed throughout all the ovarian carcinoma subtypes (fig $1 \mathrm{C}$ ), although it was not of prognostic value in this study. These results suggested that VEGF may be involved in the process of invasion and angiogenesis in serous tumours. 
It also supports the notion that tumours initially do not require an extensive vasculature because they obtain their nutrients through diffusion. The high VEGF-C values seen in ovarian cancer imply that lymphangiogenesis is important in ovarian cancer.

Yamamoto and colleagues ${ }^{149}$ reported a higher proportion of VEGF positive malignant tumours and strong VEGF immunostaining in clear cell ovarian tumours, suggesting that the growth of peritoneal metastases is dependent on neovasculature, and that VEGF may regulate angiogenesis in these deposits. Siddiqui and colleagues ${ }^{150}$ (and LF Wong Te Fong et al. Quantification of angiogenesis in primary and metastatic epithelian ovarian carcinomas. Presented at the Proceedings of the British Association of Cancer Research, July 2000, Glasgow) showed that VEGF expression within omental metastases $(n=61)$ is an independent prognostic indicator in patients with EOC, and that it also correlates with preoperative CAl 25 values and the extent of omental involvement. In addition to the prognostic implications of this work, it also served to highlight the extent to which tumour masses can become "'contaminated" by blood vessels. Many such vessels are very small and deformed, containing tortuosities, corkscrew structures, blind ends, and abnormal branching characteristics, thus making many of them almost impossible to detect in a normal haematoxylin and eosin stained tissue section. Consequently, the degree of tumour angiogenesis had been underestimated, and hence less appreciated, before the publication of this type of work.

The consistent message in these various studies is the potential importance of angiogenesis, as a prognostic tool, during transformation and acquisition of the invasive phenotype of advanced EOC. There is a relative increase in VEGF in late stage primary EOC and omental metastases compared with normal or benign tumours of the ovaries.

\section{VEGF in cyst fluid}

Yeo et al developed a sensitive and specific time resolved immunofluorometric assay for measuring VEGF in biological fluids. ${ }^{31}$ They reported findings with this assay in guinea pigs and patients with both malignant and non-malignant effusions. They also found that concentrations in human effusions provided a diagnostic test for malignancy, with a sensitivity of $66 \%$ and a specificity of $80 \%$.

On the basis of the well established fact that ovarian cancers generate fluid filled cysts that contain secretory products of cancer cells, Abu-Jawdeh and colleagues ${ }^{117}$ hypothesised that cyst fluid could be used to measure VEGF production in ovarian lesions. They determined VEGF by immunofluorimetry in cyst fluid samples obtained from a small group of patients, including seven benign, two borderline, and two malignant tumours. Substantially higher VEGF concentrations were detected in the cyst fluid samples of the two malignant and two borderline tumours than in the seven benign serous cysts.

Using a highly sensitive enzyme linked immunosorbent assay (ELISA) Hazelton and colleagues ${ }^{151}$ measured VEGF in ovarian cyst fluid obtained from a larger group of patients ( 13 ovarian cancer, 23 benign cysts and cystadenoma, five borderline tumours, and eight functional cysts). They also measured bFGF which, like VEGF, is thought to be a regulator of tumour angiogenesis. ${ }^{152} 153$ Their results showed that malignant ovarian cysts have greatly raised concentrations of VEGF. Benign ovarian cysts have either undetectable, or low amounts of VEGF, whereas borderline tumours secrete low to intermediate amounts of VEGF. In malignant cysts, bFGF values were either undetectable, or very low, and no significant differences were found in bFGF values among malignant, benign, borderline, and functional cysts.

These findings indicate that VEGF concentrations in ovarian cyst fluid may represent a useful biomarker of angiogenesis and tumour progression.

\section{VEGF in ascitic fluid}

EOC is characterised by widespread intraperitoneal carcinoma and the formation of large volumes of ascitic fluid. ${ }^{143}$ McClure and colleagues ${ }^{154}$ investigated the role of VEGF in ovarian hyperstimulation syndrome (OHSS), which is characterised by massive transduction of protein rich fluid from the vascular space into the peritoneal cavity and, to a lesser extent, pleural and pericardial cavities. They showed that VEGF is the major capillary permeability factor in OHSS ascites. Seventy per cent of the capillary permeability activity in OHSS ascites was neutralised by recombinant human VEGF antiserum.

In the ascites fluid of human ovarian cancer cell line OVCAR-5 grown in mice, Folkman ${ }^{155}$ found VEGF concentrations of more than $6000 \mathrm{pg} / \mathrm{ml}$ and, in the same mice, serum concentrations in the range of only $30 \mathrm{pg} / \mathrm{ml}$. When OVCAR-5 cells were grown in vitro, VEGF values in the conditioned medium reached greater than $1400 \mathrm{pg} / \mathrm{ml}$, compared with less than $30 \mathrm{pg} / \mathrm{ml}$ for control medium without the tumour cells. In a patient with ovarian cancer, VEGF concentrations in the ascitic fluid were greater than $13000 \mathrm{pg} / \mathrm{ml} .^{155}$

Mesiano and colleagues ${ }^{146}$ directly assessed the role of VEGF in the growth and ascites formation associated with EOC. To that end, they used the human ovarian carcinoma cell line SKOV-3 to develop an in vivo model of ovarian cancer in immunodeficient mice that mimicked the intraperitoneal carcinoma and ascites production seen in women with this disease. They then used a function blocking monoclonal antibody (A4.6.1), which blocks the access of VEGF to both the VEGF-R1 and VEGF-R2 receptors, thereby specifically inhibiting tumour derived VEGF activity, and then they assessed the consequences on tumour growth, ascites formation, and disease progression. A4.6.1 significantly inhibited subcutaneous SKOV-3 tumour growth compared with controls. However, tumour growth resumed when A4.6.1 treatment was discontinued. In mice bearing intraperitoneal tumours (IP mice), ascites production and intraperitoneal carcinoma were detected three to seven weeks after SKOV-3 inoculation. A4.6.1 completely inhibited ascites production in IP mice, although it only partially inhibited intraperitoneal tumour growth. When A4.6.1 treatment was stopped, IP mice rapidly (within two weeks) developed ascites and became cachectic.

These data suggest that in ovarian cancer, tumour derived VEGF is obligatory for ascites formation. VEGF may play a major role in the progression of EOC by influencing both tumour growth through its promotion of tumour angiogenesis, and ascites production through its stimulation of vascular permeability. Neutralisation of VEGF activity may have clinical applications in inhibiting malignant ascites formation in EOC.

\section{VEGF in the serum of patients with EOC}

Overexpression of VEGF by ovarian cancer cells is a major mediator of angiogenesis in this tumour type and serum values may therefore serve as a prognostic tool. Kondo and colleagues $^{156}$ developed an ELISA for VEGF which revealed that concentrations of this growth factor in the sera of mice were significantly increased from undetectable by subcutaneous transplantation with a solid tumour. They also measured VEGF values in serum specimens obtained from patients with several types of cancer, including ovarian cancer $(n=9)$. Sera of individuals with no sign of disease (normal, $n=26$ ) were also tested. VEGF values in the sera from the patients with EOC were significantly higher than those in the normal sera (around the detection limit of the assay).

Tempfer et al evaluated VEGF values in pretreatment serum samples of 60 patients with EOC (stages I-V). ${ }^{157}$ They found that $25 \%$ of patients with EOC had raised serum concentrations of VEGF. The median VEGF serum concentration in patients with EOC was $466 \mathrm{pg} / \mathrm{ml}$ (range, 68-284 pg/ml). The $75 \%$ quartile was $826 \mathrm{pg} / \mathrm{ml}$. These patients had significantly 
shorter overall and disease free survival. In a multivariate regression model considering tumour stage, lymph node involvement, and histological grade, serum VEGF proved to be an independent prognostic factor. This finding supports the proposal that serum concentrations of VEGF are not indicative of tumour bulk, but of strong tumour proliferation.

If these studies are confirmed in larger series, pretreatment serum VEGF values should be regarded as an additional factor for predicting outcome in patients with EOC. Owing to its independence from established prognostic factors, VEGF could be used for prognostic information in clinically relevant EOC subsets such as early stage or lymph node negative ovarian cancers. ${ }^{157}$

\section{VEGF and prognosis in EOC}

There have been few studies to date examining the prognostic value of VEGF in EOC. In one, Paley et al assessed VEGF by in situ hybridisation in a cohort of borderline patients and those with stage I and stage II EOC. ${ }^{142}$ They found that VEGF expression was a significant and independent predictor for shorter relapse free survival and overall survival. Wong Te Fong et al reported that the five year survival rates of patients with EOC whose tumours were positive for VEGF were significantly worse than those of patients with VEGF negative tumours. ${ }^{158}$ Siddiqui and colleagues ${ }^{150}$ reported that VEGF expression (as assessed by immunohistochemistry) in omental specimens (from 66 patients with EOC) significantly correlated with survival, independent of the stage of the disease. The degree of VEGF expression was found to correlate with the extent of the omental disease, being highest in those patients where the omentum was "caked" with cancer.

These limited data show that VEGF may have an important role to play in the prognosis of EOC, as a negative predictor for patients with early and late stage presentations.

\section{PD-ECGF/TP in ovarian tissue and omental metastases}

Fox and colleagues ${ }^{74}$ raised a monoclonal antibody against recombinant PD-ECFG/TP and immunohistochemically examined its expression in a range of normal human tissues, including ovary, which stained positive. Reynolds and colleagues ${ }^{141}$ studied the expression of mRNA coding for four angiogenic factors in normal ovaries, benign, and malignant ovarian tumours: PD-ECGF/TP, VEGF, bFGF, and TGF- $\beta$. The sight of sampling (areas of high velocity blood flow) was directed by transvaginal colour Doppler imaging performed within 24 hours of surgery. All four factors were expressed to some extent, but no association with malignancy was found for the expression of bFGF or TGF- $\beta$. A weak association of mRNA expression was found for VEGF, and overexpression of PD-ECGF/TP mRNA in malignant tissue compared with benign tumours was highly significant; the lowest values were found in postmenopausal ovaries and six ovarian carcinoma cell lines. The tumour sample treated with chemotherapy before surgery had the lowest degree of expression of all the tumours, including both benign and malignant. PD-ECGF/TP was also overexpressed in the corpus luteum and the secretory phase, premenopausal ovary.

\section{"Vascular endothelial growth factor may have an important role to play in the prognosis of epithelian ovarian cancer, as a negative predictor for patients with early and late stage presentations"}

Wong Te Fong et al assessed the degree of neovascularisation in a selection of normal ovaries, benign cystadenomas, ovarian borderline, and malignant tumours. ${ }^{158}$ Their results showed that two of the 10 normal ovaries were positive for PD-ECGF/TP expression and, of the seven premenopausal and the three postmenopausal specimens, both positive results occurred in premenopausal ovaries. These results support the notion that angiogenesis is a component of normal ovarian follicular and corpus luteum development. Furthermore, they showed that PD-ECGF/TP expression increased from normal, benign, borderline, and malignant ovarian tumours (although not significantly), and high PD-ECGF/TP expression correlated with poor survival.

Several other studies have found positive immunohistochemical expression of PD-ECGF/TP in EOCs (fig 1B). ${ }^{141}$ Similarly, Nakanishi and colleagues ${ }^{159}$ found that patients with advanced ovarian carcinomas showed an increase of PDECGF/TP expression in stromal cells. Fujiwaki et al showed that PD-ECGF/TP mRNA was significantly higher in EOC specimens than in normal ovary specimens. ${ }^{54}$

These various results indicate that, similar to VEGF, PD-ECGF/TP is of importance in the progression of early ovarian carcinomas and may also have some prognostic relevance.

\section{MVD in ovarian tissue and omental metastases}

In several studies, the activity of angiogenesis has been evaluated by the measurement of MVD. Amis et al studied microvascularisation in benign and malignant ovarian tumours (normal, 28; benign, 23; EOC, 36; borderline, two; unpublished data, 2002). Anti-vWF antibody was used as an endothelial marker. MVD was analysed in 97 paraffin wax embedded sections of ovarian samples of different histological subtypes, using a Quantimet 500+ image analyser. Despite following a widely described methodology, ${ }^{110}{ }^{115}$ the MVD values were similar in malignant tumours and benign tumours. It seems that tumour heterogeneity with respect to MVD between different areas of the same section, or between corresponding areas in different sections and between different blocks from the same tumours was partly accountable. ${ }^{108} 160161$ The similar MVDs in the benign and malignant tumours suggested that in ovarian tumours, angiogenesis is responsible for tumour growth rather than malignant transformation. These findings are consistent with the data of Orre et $a{ }^{1}{ }^{137}$ showing that the average microvessel counts in malignant serous and benign ovarian tumours, using anti-vWF, were similar and significantly less compared with other markers. This was thought to result from the reduced or even absent expression of vWF factor antigen in the smaller less mature microvessels of many tumours. ${ }^{162}$ Shamin and colleagues also found that MVD values in mucinous carcinomas were significantly higher than those of the serous adenocarcinomas, consistent with the results of other groups (fig lD). ${ }^{137} 163$

Nakanishi et al studied EOC and found that angiogenesis was equally stimulated regardless of stage. ${ }^{164}$ They suggested that angiogenesis might be induced differently, depending on the organ involved and the histological type of the tumour. The MVD in mucinous adenocarcinoma was the highest among the histological types, and that of clear cell carcinoma was significantly lower than that of the others. It is likely that angiogenesis is necessary for cancer cell growth and allows tumours to increase in volume, but that other mechanisms may play a crucial role in tumour progression in EOC.

Orre et al studied the association between raised MVD values in benign, mucinous, and serous tumours of the ovary ${ }^{137}$ MVD in ovarian tumours was studied with antibodies to CD31/PECAM-1, CD34, and vWF in relation to the different histological subtypes, stage, and patient outcome. CD31/ PECAM-1 and CD34 immunostaining revealed increased MVD in both the HVD and average vessel density (AVD) regions of mucinous compared with serous and benign tumours. This staining also revealed increased MVD in early stage mucinous tumours compared with that seen in both early and late stage serous tumours. Reduced vWF compared with CD31/PECAM-1 and CD34 immunostaining was seen in both borderline and malignant mucinous and serous tumours, but not in benign tumours. Orre's results ${ }^{137}$ contradict the putative association between increased MVD and poor 
prognosis, ${ }^{163}{ }^{165}$ and therefore imply that the degree and control of angiogenesis may differ between ovarian tumour types.

\section{"Rather then spreading via the vasculature, ovarian tumours generally spread via peritoneal dissemination, and tumour angiogenesis is unlikely to play a role in this type of spread"}

Abulafia and colleagues ${ }^{166}$ assessed angiogenesis in the ovaries of two groups of women: (1) 49 consecutive women with primary stage I invasive disease and (2) 34 women with borderline tumours. Microvessels were highlighted by staining them for vWF. MVD was tested statistically, by various methods, for correlation with several related variables such as: patient age, race, parity, previous contraceptive use, histological type, tumour grade, tumour size, ascites, tumour excrescences, and disease free and overall survival. The MVD values of the ovarian specimens from group 1 were significantly higher than those of group 2. These results imply that the angiogenic switch occurs between benign ovarian epithelium and borderline disease. Therefore, angiogenesis becomes intensified with invasive capability. Among women with borderline disease, MVD did not differ significantly between serous and mucinous carcinomas. There was no correlation between MVD and age, tumour grade, tumour size, ascites, or tumour excrescences. Abulafia and colleagues ${ }^{166}$ suggested that tumour vascularity as assessed by immunohistochemical MVD might help gynaecologists and pathologists to differentiate between borderline and invasive tumours when the precise diagnosis is unclear.

In solid tumours, including EOC, ${ }^{159} 165166$ there is a significant correlation between the incidence of metastasis and MVD in hotspot areas. These areas are thought to represent regions of ongoing tumour angiogenesis, in addition to the site of tumour cell entry into the circulation. ${ }^{167}$ However, rather then spreading via the vasculature, ovarian tumours generally spread via peritoneal dissemination, ${ }^{2}$ and tumour angiogenesis is unlikely to play a role in this type of spread. The growth of the primary ovarian tumour and its peritoneal metastases is dependent on continued blood vessel growth. ${ }^{168}$ Regions other than vascular hotspots may contribute to this growth.

\section{MVD and the expression of angiogenesis in EOC}

Nakanishi et al studied the association of VEGF and TGF- $\beta$ with MVD and assessed the significance of their expression as prognostic factors in EOC. ${ }^{164}$ Sixty specimens of EOC were immunohistochemically stained for VEGF and TGF- $\beta$. Seventy eight per cent of them expressed VEGF and 57\% expressed TGF- $\beta$. No correlation between the intensity of VEGF or the intensity of TGF- $\beta$ immunostaining and FIGO stage was found. However, the intensity of staining for VEGF in mucinous adenocarcinomas was significantly stronger then that seen in endometrioid adenocarcinomas and clear cell carcinomas. In addition, no correlation was found between VEGF or TGF- $\beta$ immunoreactivity and primary tumour size, nodal status, and volume of ascites (or survival in the case of VEGF). Nakanishi et al found that there was a tendency (although not significant) for MVD in VEGF rich tumours to be higher than in VEGF poor tumours. However, the MVD of VEGF rich/TGF- $\beta$ positive tumours was significantly higher than that of VEGF poor/TGF- $\beta$ negative tumours. In serous adenocarcinomas, the MVD in TGF- $\beta$ positive tumours was significantly higher than that in TGF- $\beta$ negative tumours. This study indicates that angiogenesis is an early event in EOC and is regulated differentially among the different histological types of tumours; VEGF and TGF- $\beta$ cooperate to drive angiogenesis as measured by MVD.

Orre et al returned to investigate whether the expression of VEGF and its receptors and EOC proliferation differ between ovarian tumour types and regions of the vasculature. ${ }^{169}$ VEGF,
VEGFR-1, VEGFR-2, and microvessels were assessed immunohistochemically and in situ hybridisation of was used to assess VEGF mRNA expression in regions of HVD and AVD in sections of different ovarian tumour types. Thus, with these combined methods, Orre and colleagues ${ }^{169}$ were better equipped then before to test the hypotheses that the expression of VEGF and its receptors and EOC proliferation would be associated with increased tumour vascularisation, thereby establishing themselves to be of prognostic and/or predictive value. However, the results were not conclusive and VEGF immunostaining was not significantly stronger in HVD regions of malignant compared with borderline serous tumours. More importantly, VEGF immunostaining did not differ between tumour types; however, the proportion of VEGFR-1 and VEGFR-2 positive vessels was significantly lower in mucinous tumours, and no differences were seen between HVD and AVD regions. A VEGF mRNA signal was seen in two of seven borderline mucinous tumours, eight of 14 malignant serous tumours, and five of 13 benign tumours. A negative correlation between VEGFR-1 immunostaining and MVD was seen in benign and serous tumours. However, the EOC proliferation index (assessed with the marker PCNA) and VEGFR-1 positive samples were positively correlated in benign tumours.

Again, these results suggested that angiogenesis is an early event in EOC and is regulated differentially among the different histological subtypes of tumours ${ }^{164}$; VEGF may play a role in the control of angiogenesis in serous and benign tumours, ${ }^{169}$ but it does not contribute to higher MVD values in mucinous tumours or influence the heterogeneity of MVD in ovarian tumours, as has been reported previously. ${ }^{137}$

\section{MVD and prognosis in EOC}

Weidner and colleagues ${ }^{170}$ showed that MVD, assessed by immunohistochemical staining for endothelial cells, was an independent prognostic factor in breast carcinoma. MVD has since been reported as a possible prognostic indicator in numerous human solid tumours including breast, melanoma, ${ }^{136}$ prostate,${ }^{171}$ non-small cell lung, ${ }^{172}$ gastric, ${ }^{173}$ and colorectal carcinoma. ${ }^{174} 175$

van Diest et al were the first to assess the prognostic value of MVD in advanced EOC (table 1). ${ }^{176}$ All tumours studied $(\mathrm{n}=49)$ were of the epithelial type, stages III or IV. The patients were treated by debulking surgery and cisplatin based chemotherapy. Staining of microvessels was performed on tumour material (routinely processed and embedded in paraffin wax), by immunohistochemistry with anti-vWF antibody. Microvessels were counted according to a standardised protocol. In contrast to breast cancer and melanoma, in this study MVD showed no association with other prognostic variables tested such as stage, bulky disease, grade, DNA ploidy, volume percentage epithelium, mitotic activity index, and mean nuclear area. However, in survival analysis (overall survival time between date of first operation and death of recurrent disease), a tendency for worse prognosis with higher MVD was found, although the results were not significant. In addition, a multivariate survival analysis found no additional prognostic value of MVD compared with the other prognostic factors tested. The conclusion from this study was that, although a tendency for worse survival with higher MVD had been found, vascularity did not seem to have a significant impact on survival of adequately debulked patients with advanced ovarian cancer treated with cisplatin.

In another study, Hollingsworth et al assessed vascularity in 43 advanced stage (III and IV) patients with EOC, using CD34. ${ }^{165}$ MVD and stage were associated with overall and disease free survival as assessed by Kaplan-Meier analysis. The plots showed that higher stage and higher AVD, at both low and high magnification, confer a worse prognosis for DFS. In addition, the plots suggested that higher stage and HVD at 


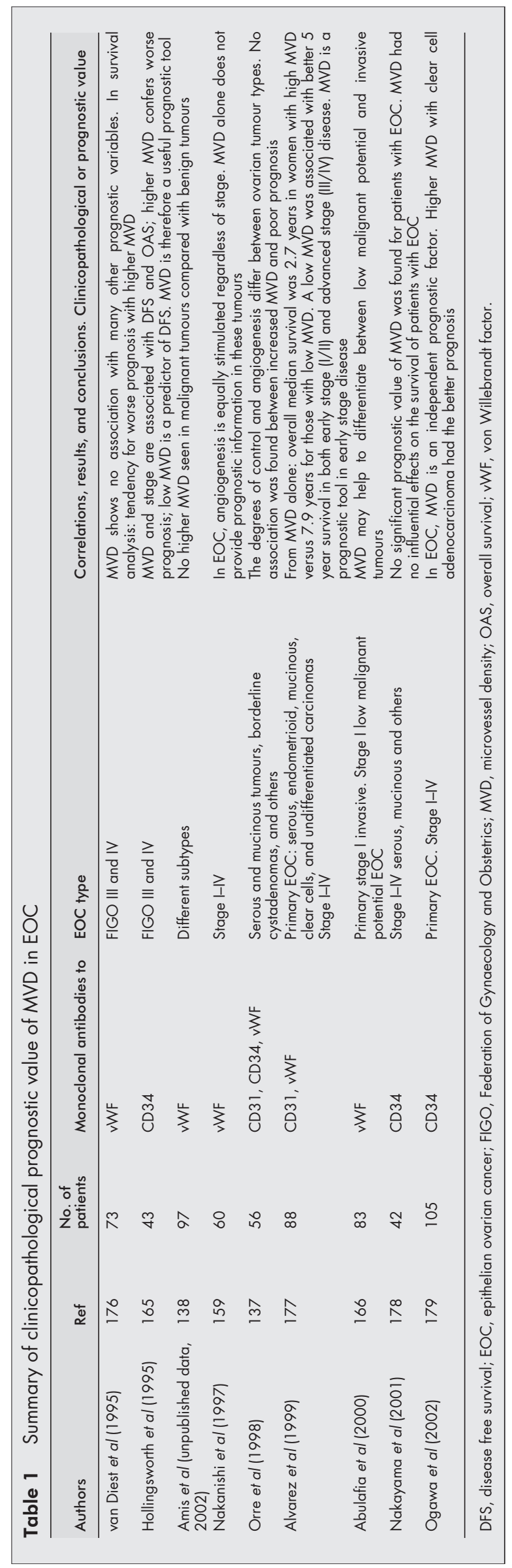

$\times 200$ and $\times 400$ magnification show a trend to worse overall survival. In contrast, a low AVD was a significant predictor of improved DFS. These results suggested that the analysis of MVD might be a useful prognostic factor in advanced stage EOC.

Alvarez et al attempted to characterise the degree of angiogenesis in EOC to determine whether neovascularisation has prognostic significance for survival. ${ }^{177}$ Tissue sections from 88 patients with ovarian cancer were examined immunohistochemically for angiogenesis after staining with antihuman endothelial cell antibodies specific to vWF and CD3l/ PECAM-1. Individual MVD values were quantified by light microscopy at high power ( $\times 400$ magnification). Overall median survival was 2.7 years in women with tumours with high MVD values compared with 7.9 years in those with low MVD values. A low MVD was associated with better five year survival in both early stage (I and II) and advanced stage (III and IV) disease. These data suggest that the degree of neovascularisation may have prognostic significance in EOC, particularly for women with early stage disease. In that group of women, the degree of angiogenesis may allow the selection of women at high risk of recurrence who may benefit from aggressive adjuvant chemotherapy.

In recent years, more effort has been invested in the evaluation of the prognostic feasibility of angiogenesis in EOC. Nakanishi et al studied the association of VEGF and TGF- $\beta$ with MVD and assessed the significance of their expression as prognostic factors in ovarian cancer. ${ }^{164}$ The expression of VEGF and TGF- $\beta$ was associated with the promotion of angiogenesis and the expression of TGF- $\beta$ may be considered as a prognostic indicator in EOC.

"The clinicopathological role of angiogenesis should be analysed taking into account the histological subtype"

Recently, Ogawa and colleagues ${ }^{179}$ studied the prognostic relevance of MVD, vascular cuffing, VEGF expression, and clinicopathological parameters in EOC. Surgical specimens from 105 primary ovarian cancers were examined for vascularisation and VEGF expression by immunohistochemical staining. The higher MVD group and the positive VEGF group were associated with better DFS only in early stage tumours. Patients with advanced stage tumours, or with early stage tumours of a non-clear cell subtype, showed no association between MVD and survival. The significant association between MVD and better DFS was recognised only in those patients with clear cell adenocarcinomas. A multivariate analysis revealed that MVD correlated independently with DFS. In these histological subtypes, MVD was found to be an independent prognostic factor. The group concluded that the clinicopathological role of angiogenesis should be analysed taking into account the histological subtype. They also found that VEGF was often expressed heterogeneously in a slide. They suggested that this heterogeneity might be one of the reasons for the variable association between VEGF expression and prognosis in different studies.

\section{ANGIOGENESIS IN EOC COMPARED WITH ANGIOGENESIS IN BREAST CANCER}

As can be seen from the studies described above for MVD in EOC, ${ }^{137} 163165166$ 180-183 the clinicopathological relevance of angiogenesis is still not clear (table 1). The results cannot be compared easily, because of the interlaboratory differences in tissue fixation, processing, and staining technique, experience of the observer in selecting vascular hotspots, and the vessel counting technique. Most of the studies of angiogenesis in clinical samples described here have used a variation of the method described by Weidner et al in their study of angiogenesis in breast carcinoma. ${ }^{170}$ The sections are stained immunohistochemically with a marker for endothelial cells, and the 
capillaries are counted to determine MVD. Angiogenesis assessed by these methods has been widely accepted as an independent prognostic factor in human breast carcinoma, but not in EOC. To find out how rich angiogenesis is in EOC, Nakayama et al performed a comparative analysis of MVD in ovarian and breast carcinoma, at the same time. ${ }^{178}$ This comparative study found that MVD was lower in EOC than in breast carcinoma. In addition, 19 of the 42 cases of EOC revealed an MVD less than $14 / \mathrm{mm}^{2}$, which was the lowest MVD value seen in breast carcinoma. Moreover, the degree of variation of MVD in EOC was smaller than that in breast carcinoma. The profile of MVD in breast carcinoma was very similar to that previously identified. ${ }^{136}$ Therefore, the data indicate that in EOC MVD may not be so rich as in breast carcinoma.

Because angiogenesis, as assessed by MVD, did not correlate with the progression of EOC in the study of Nakayama et al (table 1), ${ }^{178}$ or in the previous studies, it seems that angiogenesis in the prevascular phase may be involved in the progression of ovarian neoplasms. However, angiogenesis in the vascular phase may not play an important role in EOC. The results of Nakayama et al revealed no significant prognostic value of MVD in patients with EOC. In contrast, MVD may be a prognostic factor in patients with breast carcinoma.

So far, there has been no report showing a significant prognostic value of MVD by multivariate analysis in EOC. This has been explained ${ }^{178}$ using the present data and previous findings as follows:

- Angiogenesis in EOC may not be as rich as that seen in other types of carcinoma, in which angiogenesis is an independent prognostic factor.

- The degree of variation of angiogenesis in each EOC may not be large enough to serve as a prognostic indicator.

- Angiogenesis in EOC seems to be dependent on histopathological subtype, ${ }^{137} 163^{165} 5^{180-184}$ as described above.

In summary, this recent comparative analysis of MVD in EOC with that in breast carcinoma ${ }^{178}$ indicates that angiogenesis may play an important role in the progression of breast neoplasms, but not in the progression of ovarian carcinomas.

\section{CONCLUSIONS}

The high mortality rate of ovarian cancer results predominantly from the occult progression of the tumour within the peritoneal cavity, with the initial diagnosis usually only being made at an advanced stage. Modifications in chemotherapy and/or surgery are unlikely in the near future to improve the poor prognosis associated with this disease. An improved understanding of the mechanisms regulating the growth of EOC cells may eventually lead to techniques that facilitate early diagnosis, establish the prognosis, or determine the response to treatment. Eventually, it may even be possible to design effective target treatments that will work by interfering with the biochemical processes that govern the growth of EOC cells.

\section{ACKNOWLEDGEMENT}

We thank Miss LF Long Te Fong and Mr F Moll for preparing the photomicrographs for this review.

\section{Authors' affiliations}

E S Bamberger, Department of Biology, University of Haifa at Oranim, Tivon 36006, Israel

C W Perrett, Department of Obstetrics and Gynaecology, Royal Free and University College Medical School, Royal Free Campus, Rowland Hill Street, London NW3 2PF, UK

\section{REFERENCES}

1 Czernobilsky B. Common epithelial tumors of the ovary. Blaustein's pathology of the female genital tract, RJ Kurman, ed. New York: Springer-Verlag, 1987.
Take home messages

- Angiogenesis is essential for solid tumour growth and metastasis

- Many tumours express angiogenic factors, thereby promoting their own vascularisation in a paracrine manner

- The angiogenic stimulator vascular endothelial growth factor (VEGF) has been found in ovarian tumour tissue, omental metastases, cystic and ascitic fluids, and the serum of patients with epithelian ovarian cancer (EOC)

- In EOC, VEGF values in ovarian cyst fluid are a useful biomarker of angiogenesis and tumour progression

- Tumour derived VEGF is obligatory for ascites formation and serum VEGF is an independent prognostic factor, indicative of strong tumour proliferation (of all histological subtypes)

- VEGF may play a role in the control of angiogenesis in both malignant serous and benign tumours (of all subtypes) and, therefore, is a potential independent negative predictor for patients with early and late stage presentations

- The expression of platelet derived endothelial cell growth factor/thymidine phosphorylase (PD-ECGF/TP) is also higher than normal in patients with advanced ovarian carcinomas

- The analysis of tumour vascularisation by microvessel density (MVD) is used as a prognostic factor in various cancers, but in EOC, no correlation has been found between MVD and age, tumour grade, tumour size, ascites, or tumour growth, although it varied greatly among the histological subtypes

- Angiogenesis is therefore an early event in EOC and is regulated differentially among the different histological subtypes of tumour and its clinicopathological role should be analysed taking into account the histological type

- MVD and VEGF expression do not appear to be as useful in predicting prognosis as they are in breast carcinoma, so that angiogenesis in EOC may not be as rich as that seen in other types of carcinoma, in which it is an independent prognostic factor

2 Kristensen GB, Trope C. Epithelian ovarian carcinoma. Lancet 1997;349:113-17.

3 Land A. Ovulation, ovulation induction and ovarian carcinoma. Ballieres Clin Obstet Gynaecol 1993;7:455.

4 Russell P, Bannatyne P. Surgical pathology of the ovaries, Appendix B. Edinburgh: Churchill Livingstone, 1989

5 Serove S, Sculy R, Sobin L. The molecular pathogenesis of ovarian cancer. In: International histological classification of tumours. No. 9 Histological typing of ovarian tumours. Geneva: World Health Organisation, 1973:46-50.

6 Krigman H, Bentley H, Robboy SJ. Pathology of epithelian ovarian tumours. Clin Obstet Gynecol 1994;37:475-91.

7 Serov SF, Scully RE, Sobin LH. Histological typing of ovarian tumours. In: International histological classification of tumours, No. 9. Geneva: World Health Organisation:17-54.

8 Cannistra SA. Cancer of the ovary. N Engl J Med 1993;329:1550-9.

9 Fox H, Singh N. Pathology of epithelian ovarian cancer. In: Jacobs IJ, Shepherd JH, Oram DH, et al, eds. Ovarian cancer, 2nd ed. Oxford University Press, 2002:57-66.

10 Green HSN. Heterologous transplantation of mammalian tumours. The transfer of human tumours to alien species. J Exp Med 1941;73:461-8.

11 Folkman J. What is the evidence that tumors are angiogenesis dependent? J Natl Cancer Inst 1990;82:4-6.

12 Sharma RA, Harris AL, Dalgleish AG, et al. Angiogenesis as a biomarker and target in cancer chemoprevention. Lancet Oncol $2001 ; 2: 726-31$

13 Folkman J. Tumor angiogenesis: therapeutic implications. N Engl J Med 1971;285: 1182-6.

14 Folkman J. Anti-angiogenesis: new concept for therapy of solid tumors. Ann Surg 1972;175:409-16.

15 Krebel RS. Tumour angiogenesis: past, present and the near future. Carcinogenesis 2000;21:505-15.

16 Folkman J, Watson K, Ingber D, et al. Induction of angiogenesis during the transition from hyperplasia to neoplasia. Nature 1989;339:58-61.

17 Folkman J, Klagsbrun M. Vascular physiology: a family of angiogenic peptides. Nature 1987;329:671-2

18 Mesiano S, Ferrara N, Jaffe RB. Role of vascular endothelial growth factor in ovarian cancer. Inhibition of ascites formation by immunoneutralization. Am J Pathol 1998:153:1249-56.

19 Brown LF, Guidi AJ, Tognazzi K, et al. Vascular permeability factor/vascular endothelial growth factor and vascular stroma formation 
in neoplasia: insights from in situ hybridization studies. J Histochem Cytochem 1998; 46:569-76.

20 Holmgren L, O'Reilly MS, Folkman J. Dormancy of micrometastases: balance proliferation and apoptosis in the presence of angiogenesis suppression. Nat Med 1995;1:149-53.

21 Parangi S, O'Reilly MS, Christofori G, et al. Angiogenesis therapy of transgenic mice impairs de novo tumour growth. Proc Natl Acad Sci U S A 1996;93:2002-7.

22 Dobbs SP, Hewett PW, Johanson IR, et al. Angiogenesis is associated with VEGF expression in cervical intraepithelial neoplasia. Br J Cancer 1997;76:1410-15

23 Maclean AB, Reid WMN, Rolfe KG, et al. The role of angiogenesis in benign, premalignant and malignant vulvar lesions. J Reprod Med 2000;45:609-12.

24 Ferrara N. Vascular endothelial growth factor: molecular and biological aspects. Curr Top Microbiol Immunol 1999;237:1-30.

25 Carmeliet P, Rakesh K. Angiogenesis in cancer and other diseases. Nature 2000;407:249-57.

26 Yancopoulos GD, Davis S, Gale NW, et al. Vascular specific growth factors and blood vessel formation. Nature 2000;407:242-8

27 Gale NW, Yancopoulos GD. Growth factors acting via endothelial cell-specific receptor tyrosine kinases: VEGFs, angiopoietins, and ephrins in vascular development. Genes Dev 1999;13:1055-66.

28 Hirschi KK, Rohovsky SA, Beck LH, et al. Endothelial cells modulate the proliferation of mural cell precursors via platelet-derived growth factor-BB and heterotypic cell contact. Circ Res 1999;84:298-305.

29 Dvorak HF, Brown LF, Detmar M, et al. Vascular permeability factor/vascular endothelial growth factor, microvascular hyperpermeability and angiogenesis. Am J Pathol 1995; 146:1029-39.

30 Senger DR, Van De Water L, Brown LF, et al. Vascular permeability factor (VPE, VEGF) in tumor biology. Cancer Metastasis Rev 1993; 12:303-24

31 Yeo KW, Wang HH, Nagy JA, et al. Vascular permeability factor (vascular endothelial growth factor) in guinea pig and human tumour and inflammatory effusions. Cancer Res 1993;53:2912-18.

32 Dvorak HF, Nagy JA, Berse B, et al. Vascular permeability factor, fibrin and the pathogenesis of tumor stroma formation. Ann New York Acad Sci 1992;667:101-11.

33 Nagy JA, Brown LF, Senger DR, et al. Pathogenesis of tumour stroma generation: a critical role for leaky blood vessels and fibrin deposition. Biochim Biophys Acta 1988:948:305-26.

34 Shweiki D, Itin A, Soffer D, et al. Vascular endothelial growth factor induced by hypoxia may mediate hypoxia-initiated angiogenesis. Nature 1992;359:843-5.

35 Connolly DT, Heuvelman DM, Nelson R, et al. Tumor vascular permeability factor stimulates endothelial cell growth and angiogenesis. $J$ Clin Invest 1989;84:1470-8.

$36 \mathrm{Kim} \mathrm{KJ}$, Li B, Winer J, et al. Inhibition of vascular endothelial growth factor-induced angiogenesis suppresses tumour growth in vivo. Nature 1993; 362:841-4.

37 Plate KH, Breier G, Weich HA, et al. Vascular endothelial growth factor is a potential tumour angiogenesis factor in human gliomas in vivo. Nature 1992;359:845-8.

38 Conn G, Bayne ML, Soderman DD, et al. Amino acid and cDNA sequence of a vascular endothelial cell mitogen that is homologous to platelet-derived growth factor. Proc Natl Acad Sci U S A 1990;87:2628-32

39 Ferrara N, Henzel WJ. Pituitary follicular cells secrete a novel heparin-binding growth factor specific for vascular endothelial cells. Biochem Biophys Res Commun 1989;161:851-8.

40 Gospodarowicz D, Abraham JA, Schilling J. Isolation and characterization of a vascular endothelial cell mitogen produced by pituitary-derived folliculostellate cells. Proc Natl Acad Sci U S A 1989;86:7311-15

41 Keck PJ, Hauser SD, Krivi G, et al. Vascular permeability factor, an endothelial cell mitogen related to PDGF. Science 1989;246:1309-12.

42 Leung DW, Cachiane G, Kuang WJ, et al. Vascular endothelial growth factor is a secreted angiogenic mitogen. Science 1989;246:1306-9.

43 Ferrara N, Jakeman L, Houck K, et al. Molecular and biological properties of the vascular endothelial growth factor family of proteins. Endocr Rev 1992;13:18-32.

44 Ferrara N. Vascular endothelial growth factor. Eur J Cancer 1996;32:2413-22

45 Zachary I. Molecules in focus: vascular endothelial growth factor. Int J Biochem Cell Biol 1998;30:1 169-74.

46 Alon T, Hemo I, Itin A, et al. Vascular endothelial growth factor acts as a survival factor for newly formed retinal vessels and has implications for retinopathy of prematurity. Nat Med 1995;1:1024-8.

47 Benjamin LE, Keshet E. Conditional switching of vascular endothelial growth factor (VEGF) expression in tumors: induction of endothelial cell shedding and regression of hemangioblastoma-like vessels by VEGF withdrawal. Proc Natl Acad Sci U S A 1997;94:8761-6.

48 Benjamin LE, Golijanin D, Itin A, et al. Selective ablation of immature blood vessels in established human tumours follows vascular endothelial growth factor withdrawal. J Clin Invest 1999;103:159-65.

49 Vincenti V, Cassano C, Rocchi M, et al. Assignment of the vascular endothelial growth factor gene to the human chromosome 6 p21.3. Circulation 1966;93:1493-5

50 Toi M, Hoshina S, Takayanagi T, et al. Association of vascular endothelial growth factor expression with tumour angiogenesis and the early relapse in primary breast cancer. Jpn J Cancer Res 1994;85:1045-9.
51 Olson TA Monhanraj D, Carson LF, Ramakarisnan S. Vascular permeability gene in normal and neoplastic human ovaries. Cancer Res 1994;54:276-80

52 Brown LF, Berse B, Jackman RW, et al. Increased expression of vascular permeability (vascular endothelial growth factor) and its receptors in kidney and bladder carcinomas. Am J Pathol 1993:143:1255-62.

53 Emoto $M$, Iwasaki $H$, Ishiguro $M$, et al. Angiogenesis in carcinosarcomas of the uterus: differences in the microvessel density and expression of VEGF between the epithelial and mesenchymal elements. Hum Pathol 1999:30:1232-41.

54 Fujiwaki R, Hata K, Maede $Y$, et al. VEGF expression in progression of cervical cancer: correlation with thymidine phosphorylase expression, angiogenesis, tumour cell proliferation, and apoptosis. Anticancer Res 2000;2B: 1317-22.

55 Tjalma W, Wegler J, Weyn B, et al. The association between VEGF, MVD and clinicopathological features in invasive cervical cancer. Eur Obstet Gynecol Reprod Biol 2000;92:251-7.

56 Mattern J, Koomagi R, Volm M. Vascular endothelial growth factor expression and angiogenesis in non-small cell lung carcinomas. Int $J$ Oncol 1995;6: 1058-62.

57 Witte L, Hicklin DJ, Zhu Z, et al. Monoclonal antibodies targeting the VEGF receptor-2 (Flk l/KDR) as an anti-angiogenic therapeutic strategy. Cancer Metastasis Rev 1998;17:155-61.

58 Zhu Z, Rockwell P, Lu D, et al. Inhibition of vascular endothelial growth factor-induced receptor activation with anti-kinase insert domain-containing receptor single-chain antibodies from a phage display library. Cancer Res 1998;58:3209-14.

59 Schlaeppi JM, Siemeister G, Weindel K, et al. Characterization of a new potent, in vivo neutralizing monoclonal antibody to human vascular endothelial growth factor. J Cancer Res Clin Oncol 1999;125:336-42.

60 Presta LG, Chen $\mathrm{H}, \mathrm{O}^{\prime}$ Connor SJ, et al. Humanization of an anti-vascular endothelial growth factor monoclonal antibody for the therapy of solid tumours and other disorders. Cancer Res 1997;57:4593-9.

61 Ramakrishnan S, Olson TA, Bautch VL, et al. Vascular endothelial growth factor-toxin conjugate specifically inhibits KDR/flk-1-positive endothelial cell proliferation in vitro and angiogenesis in vivo. Cancer Res 1996;56:1324-30

62 Shawver LK, Lipson KE, Fong TAT, et al. Receptor tyrosine kinases as targets for inhibition of angiogenesis. Drug Development Trends 1997;2:50-63.

63 Seo MS, Kwak N, Ozaki H, et al. Dramatic inhibition of retinal and choroidal neovascularization by oral administration of a kinase inhibitor Am J Pathol 1999;154:1743-53

64 Veikkola T, Karkkainen M, Clesson-Welsh L, et al. Regulation of angiogenesis via vascular endothelial growth factor receptors. Cancer Res 2000;60:203-12.

65 Bellomo D, Headrick JP, Silins GU, et al. Mice lacking the vascular endothelial growth factor-B gene (Vegfb) have smaller hearts, dysfunctional coronary vasculature, and impaired recovery from cardiac ischemia. Circ Res 2000;86:E29-35.

66 Olofsson B, Jeltsch M, Eriksson U, et al. Current biology of VEGF-B and VEGF-C. Curr Opin Biotechnol 1999; 10:528-35.

67 Persico MG, Vincenti V, DiPalma T. Structure, expression and receptor-binding properties of placenta growth factor (PIGF). Curr Top Microbiol Immunol 1999;237:31-40.

68 Eriksson U, Alitalo K. Structure, expression and receptor-binding properties of novel vascular endothelial growth factors. Curr Top Microbiol Immunol 1999;237:41-57

69 Soker S, Takashima S, Miao H, et al. Neuropilin-1 is expressed by endothelial and tumor cells as an isoform-specific receptor for vascular endothelial growth factor. Cell 1998;92:735-45.

70 Shalaby F, Rossant J, Yamaguchi TP, et al. Failure of blood-island formation and vasculogenesis in Flk-1-deficient mice. Nature 1995;376:62-6.

71 Hiratsuka S, Minowa O, Kuno J, et al. Flt-1 lacking the tyrosine kinase domain is sufficient for normal development and angiogenesis in mice. Proc Natl Acad Sci U S A 1998;95:9349-54

72 Taipale J, Makinen T, Arighi E, et al. Vascular endothelial growth factor receptor-3. Curr Top Microbiol Immunol 1999;237:85-96.

73 Ishikawa F, Miyazono K, Hellman U, et al. Identification of angiogenic activity and the cloning expression of platelet-derived endothelial cell growth factor. Nature 1989;338:557-61

74 Fox S, Moghaddam A, Westwood M, et al. Platelet-derived endothelial growth factor/thymidine phosphorylase expression in normal tissue: an immunohistochemical study. J Pathol 1995;176:183-90.

75 O'Brien TS, Fox SB, Dickinson AN, et al. Expression of the angiogenic factor thymidine phosphorylase/platelet-derived endothelial growth facto in primary bladder cancers. Cancer Res 1996;56:4779-804.

76 Furukawa T, Yoshimura A, Sumizawa T, et al. Angiogenic factor Nature 1992;356:668.

77 Haraguchi M, Kazutaka M, Uemura K, et al. Angiogenic activity of enzymes. Nature 1994;368:198.

78 Korhonen J, Partanen J, Armstrong E et al. Enhanced expression of the tie receptor tyrosine kinase in endothelial cells during neovascularization. Blood 1992:80:2548-55.

79 Maisonpierre PC, Goldfarb M, Yancopoulos GD, et al. Distinct rat genes with related profiles of expression define a TIE receptor tyrosine kinase family. Oncogene 1993;8:1631-7.

80 Sato TN, Qin Y, Kozak CA, et al. tie-1 and tie-2 define another class of putative receptor tyrosine kinase genes expressed in early embryonic vascular system. Proc Natl Acad Sci U S A 1993;90:9355-8. 
81 Dumont DJ, Gradwohl GJ, Fong GH, et al. The endothelial-specific receptor tyrosine kinase, tek, is a member of a new subfamily of receptors. Oncogene 1993;8:1293-301.

82 Iwama A, Hamaguchi I, Hashiyama M, et al. Molecular cloning and characterization of mouse Tie and Tek receptor tyrosine kinase genes and their expression in hematopoietic stem cells. Biochem Biophys Res Commun 1993;195:301-9.

83 Maisonpierre PC, Suri C, Jones PF, et al. Angiopoietin-2, a natura antagonist for Tie2 that disrupts in vivo angiogenesis. Science 1997; 277:55-60.

84 Holash J, Maisonpierre PC, Compton D, et al. Vessel cooption, regression and growth in tumours mediated by angiopoietins and VEGF. Science 1999;284:1994-8

85 Yancopoulos GD, Klagsbrun M, Folkman J. Vasculogenesis, angiogenesis, and growth factors: ephrins enter the fray at the border Cell 1998:93:661-4.

86 LeCouter J, Kowalski J, Foster J, et al. Identification of an angiogenic mitogen selective for endocrine gland endothelium. Nature 2001;412:877-84

87 Dameron KM, Volpert OV, Tainsky MA, et al. Control of angiogenesis in fibroblasts by $\mathrm{p} 53$ regulation of thrombospondin-1. Science 1994;265: 1582-4

88 Tolsma SS, Volpert OV, Good DJ, et al. Peptides derived from two separate domains of the matrix protein thrombospondin-1 have anti-angiogenic activity. J Cell Biol 1993;122:497-51 1 .

89 Dvorak HF, Gresser I. Microvascular injury in pathogenesis of interferon-induced necrosis of subcutaneous tumours in mice. J Nat Cancer Inst 1989;81:497-502.

90 Singh RK, Gutman M, Bucana CD, et al. Interferons $\alpha$ and $\beta$ down-regulate the expression of basic fibroblast growth factor in human carcinomas. Proc Natl Acad Sci U S A 1995;92:4562-6.

91 Ezekowitz RA, Mulliken JB, Folkman J. Interferon-2a therapy for life-threatening hemangiomas of infancy. N Engl J Med 1992; 326: 1456-63

92 Clapp C, Martial JA, Guzman RC, et al. The 16-kilodalton N-terminal fragment of human prolactin is a potent inhibitor of angiogenesis. Endocrinology 1993;133:1292-9.

93 O'Reilly MS, Holmgren L, Shing Y, et al. Angiostatin: a novel angiogenesis inhibitor that mediates the suppression of metastases by a Lewis lung carcinoma. Cell 1994;79:315-28.

94 O'Reilly MS, Boehm T, Shing Y, et al. Endostatin: an endogenous inhibitor of angiogenesis and tumor growth. Cell 1997;88:277-85

95 Zhai Y, Ni J, Jiang GW, et al. VEGI, a novel cytokine of the tumour necrosis factor family, is an angiogenesis inhibitor that suppresses the growth of colon carcinomas in vivo. FASEB J 1999;13:181-9.

96 Pike SE, Yao L, Jones KD, et al. Vasostatin, a calreticulin fragment, inhibits angiogenesis and suppresses tumour growth. J Exp Med 1998; 188:2349-56

97 Vazquez F, Hastings G, Ortega MA, et al. METH-1, a human ortholog of ADAMTS-1 and METH-2 are members of a new family of proteins with angio-inhibitory activity. J Biol Chem 1999;274:23349-57.

98 Gupta SK, Hassel T, Singh JP. A potent inhibitor of endothelial cell proliferation is generated by proteolytic cleavage of the chemokine platelet factor 4. Proc Natl Acad Sci U S A 1995;92:7799-803.

99 O'Reilly MS, Pirie-Shepherd S, Lane WS, et al. Antiangiogenic activity of the cleaved conformation of the serpin antithrombin III. Science 1999;285: 1926-8.

100 Folkman J. Angiogenesis inhibitors generated by tumours. Mol Med $1995 ; 1: 120-2$

101 Sage EH. Pieces of eight: bioactive fragments of extracellular proteins as regulators of angiogenesis. Trends Biol Sci 1999;7:182.

102 Hanahan D, Folkman J. Patterns and emerging mechanisms of the angiogenic switch during tumorigenesis. Cell 1996;86:353-64.

103 Weidner N. Tumoral vascularity as a prognostic factor in cancer patients: the evidence continues to grow. J Pathol 1998;184:119-22.

104 Jacquemier JD, Penault-Llorca FM, Bertucci F, et al. Angiogenesis as a prognostic marker in breast carcinoma with conventional adjuvant chemotherapy: a multiparametric and immunohistochemical analysis. $J$ Pathol 1998; 184:130-5

105 Takahashi Y, Kitadai Y, Bucana CD, et al. Expression of vascular endothelial growth factor and its receptor KDR, correlates with vascularity, metastasis, and proliferation of human colon cancer. Cancer Res 1995;55:3964-8.

106 Toi M, Inada K, Sizuki H, et al. Tumour angiogenesis in breast cancer: its important as a prognostic indicator and the association with vascular endothelial growth factor expression. Breast Cancer Res Treat 1995; 36: 193-204

107 Ogawa Y, Chung YS, Nakata B, et al. Microvessel quantitation in invasive breast cancer by staining for factor VIII-related antigen. $\mathrm{Br} \mathrm{J}$ Cancer 1995; 71:1297-301.

108 Bosari S, Lee AK, DeLellis RA, et al. Microvessel quantitation and prognosis in invasive breast carcinoma. Hum Pathol 1992;23:755-61.

109 Horak ER, Lee AK, Klenk N, et al. Angiogenesis assessed by platelet/endothelial cell adhesion molecule antibodies, as indicator of node metastases and survival in breast cancer. Lancet 1992;340:1 120-4

110 Weidner N, Sempel JP, Welch WR, et al. Tumour angiogenesis and metastasis correlation in invasive breast carcinoma. N Engl J Med 1991;324:1-8.

111 Carnochan P, Briggs JC, Westbury G, et al. The vascularity of cutaneous melanoma, a quantitative histological study of lesions 0.85-1.25 mm thickness. Br J Cancer 1991;64:102-7.
112 Fallowfield ME, Cook MG. The vascularity of primary cutaneous melanoma. J Pathol 1991;164:214-44.

113 Srivastava A, Laidler P, Davies RP, et al. The prognostic significance of tumour vascularity in intermediate thickness $(0.76-4.0 \mathrm{~mm}$ thick) skin melanoma: a quantitative study. Am J Pathol 1988;133:419-23.

114 Macchiarini P, Fontanini G, Hardin M, et al. Relation of neovascularization to metastasis of non-small-cell lung cancer. Lancet 1992:340: 145-6.

115 Weidner N, Carroll PR, Flax J, et al. Tumor angiogenesis correlates with metastasis in invasive prostate carcinoma. Am J Pathol 1993:143:401-9

116 Yoshiji H, Gomez DE, Shibuya M, et al. Expression of vascular endothelial growth factor, its receptor, and other angiogenic factors in human breast cancer. Cancer Res 1996;56:2013-16.

117 Abu-Jawdeh GM, Faix JD, Niloff J, et al. Strong expression of vascular permeability factor (vascular endothelial growth factor) and its receptors in ovarian borderline and malignant neoplasms. Lab Invest 1996:74:1105-15.

118 Smith-McCune KK, Weidner N. Demonstration and characterization of the angiogenic properties of cervical dysplasia. Cancer Res 1994;54:800-4

119 Brown LF, Berse B, Jackman RW, et al. Expression of vascular permeability factor (vascular endothelial growth factor) and its receptors in adenocarcinomas of the gastrointestinal tract. Cancer Res 1993:53:4727-35

120 Kitadai Y, Haruma K, Tokutomi T, et al. Significance of vessel count and vascular endothelial growth factor in human esophageal carcinoma. Clin Cancer Res 1998;4:2195-200.

121 Ohta Y, Endo Y, Tanaka M et al. Significance of vascular endothelia growth factor messenger RNA expression in primary lung cancer. Clin Cancer Res 1996:2:1411-16.

122 Albo D, Granick MS, Jhala N, et al. The relationship of angiogenesis to biological activity in human squamous cell carcinomas of the head and neck. Ann Plast Surg 1994;32:588-94.

123 Gasparini G, Weider N, Maluta S, et al. Intratumoral microvessel density and p53 protein: correlation with metastasis in head and neck squamous cell carcinoma. Int J Cancer 1993;55:739-44

124 Murray JD, Carlson GW, McLaughin K, et al. Tumor angiogenesis as a prognostic factor in laryngeal cancer. Am J Surg 1997; 174:523-6.

125 Pazouki S, Chisholm DM, Adi MM, et al. The association between fumor progression and vascularity in the oral mucosa. J Pathol 1997; 183:39-43

126 Enisma RJ, Spiro JD, Kreutzer DL. Vascular endothelial growth factor expression in head and neck squamous cell carcinoma. Am J Surg 1997; 174:513-17

127 Maeda T, Matsumura S, Hiranuma $\mathrm{H}$, et al. Expression of vascular endothelial growth factor in human oral squamous cell carcinoma: its association with fumour progression and p53 gene. J Clin Pathol 1998;51:771-5

128 Moriyama M, Kumagai S, Kawashiri S, et al. Immunohistochemical study of tumour angiogenesis in oral squamous cell carcinoma. Oral Oncol 1997:33:369-74.

129 Tae K, El-Naggar AK, Yoo E, et al. Expression of vascular endothelial growth factor and microvessel density in head and neck tumorigenesis. Clin Cancer Res 2000;6:2821-8.

130 Kato T, Kameoka S, Kimura T, et al. Prognostic significance of angiogenesis associated with long-term survival in 377 Japanese patients with breast cancer. Program and abstracts of the 23rd Annual San Antonio Breast Cancer Symposium; December 6-9, 2000; San Antonio, Texas. Abstract 568. Breast Cancer Res Treat 2000;64:132.

131 Gehani SA, Parbhoo SP, Hatter T, et al. Is angiogenesis a predictor of the development of bone metastasis? Results of immunohistochemical study using CD3 1 and factor VIII for angiogenesis assessment in primary breast cancer. Program and abstracts of the 23rd Annual San Antonio Breast Cancer Symposium; December 6-9, 2000; San Antonio, Texas. Abstract 561. Breast Cancer Res Treat 2000;64:131.

132 Fay PJ. Factor VIII function and structure. Thromb Haemost 1993;70:63-7.

133 DeLiser HM, Newman PJ, Albelda SM. Molecular and functional aspects of PECM-1/CD3 1. Immunol Today 1994;15:490-5.

134 Krause DS, Fackler M, Civin CL. CD34 structure, biology and clinical utility. Blood 1996;87:1-13

135 Kuzu L, Hicknell R, Hariss AL, et al. Heterogeneity of vascular endothelial cells with relevance to diagnosis of vascular tumours. J Clin Pathol 1992:45: 143-8

136 Toi $M$, Kashitami J, Tominaga T. Tumour angiogenesis is an independent prognostic indicator of breast carcinoma. Int J Cancer 1993;55:371-4.

137 Oree M, Lotfi-Miri M, Rogers PAW. Increased microvessel density in mucinous compared with malignant serous and benign tumours of the ovary. Br J Cancer 1998;77:2204-9.

138 Withdrawn

139 Gordon JD, Mesiano S, Zaloudek CJ, et al. Vascular endothelial growth factor localization in human ovary and fallopian tubes: possible role in reproductive function and ovarian cyst formation. J Clin Endocrinol Metab 1996;81:353-9.

140 Boocock CA, Charnock-Jones S, Sharkey AM, et al. Expression of vascular endothelial growth factor and its receptors flt and KDR in ovarian carcinoma. J Natl Cancer Inst 1995;87:506-16.

141 Reynolds K, Farzaneh F, Collins WP, et al. Association of ovarian malignancy with expression of platelet-derived endothelial cell growth factor. J Natl Cancer Inst 1994;86: 1234-8.

142 Paley PJ, Staskus KA, Gebhard K, et al. Vascular endothelial growth factor expression in early stage ovarian carcinoma. Cancer 1997;80:98-106. 
143 Perez RP, Godwin AK, Hamilton TC, et al. Ovarian cancer biology. Semin Oncol 1991;18:186-204.

144 Otsuka T, Ohkawa T, Shibata T, et al. A new potent angiogenesis inhibitor, FR-1 18487. J Microbiol Biotechnol 1991;1:163-8.

145 Mu J, Abe Y, Tsutsui T, et al. Inhibition of growth and metastasis of ovarian carcinoma by administering a drug capable of interfering with vascular endothelial growth factor activity. Jpn J Cancer Res 1996;87:963-71.

146 Messiano S, Ferrara N, Jaffe RB. Role of vascular endothelial growth factor in ovarian cancer. Am J Pathol 1998;153:1249-56.

147 Wong Te Fong LF, Kini M, Morris R, et al. Angiogenesis in primary epithelial ovarian carcinomas. Anticancer Res 2001;21:1662.

148 Wong Te Fong LF, Gammell SJ, Bamberger ES, et al. Quantification of VEGF-A and PD-ECGF/TP in normal, benign and malignant ovarian lesions. Rev Oncol 2002:4(suppl 1):122.

149 Yamamoto S, Konishi I, Koruda H, et al. Vascular endothelial growth factor levels in ovarian cyst fluid correlate with malignancy. Clin Cancer Res 1999;5:823-9.

150 Siddiqui GK, Wong Te Fong LF, Rolfe KJ, et al. The expression of VEGF-A in metastatic epithelian ovarian cancer is of prognostic significance. Br J Obstet Gynaecol 2001;108:549.

151 Hazelton D, Nicosia F, Nicosia SV. Vascular endothelial growth factor levels in ovarian cyst fluid correlate with malignancy. Clin Cancer Res 1999:5:823-9.

152 Crickard K, Gross JL, Crickard U, et al. Basic fibroblast growth factor and receptor expression in human ovarian cancer. Gynecol Oncol 1994;56:277-84.

153 Di Blasio AM, Cremonesi L, Vigano P, et al. Basic fibroblast growth factor and its receptor messenger ribonucleic acids are expressed in human ovarian epithelial neoplasms. Am J Obstet Gynecol 1993; 169:1517-23.

154 McClure N, Healy DL, Rogers PA, et al. Vascular endothelial growth factor as capillary permeability agent in ovarian hyperstimulation syndrome. Lancet 1994;344:235-6.

155 Folkman J. A new link in ovarian cancer angiogenesis: lysophphosphatidic acid and vascular endothelial growth factor expression. J Natl Cancer Inst 2001;93:734-5.

156 Kondo S, Asano M, Matsuo K, et al. Vascular endothelial growth factor/vascular permeability factor is detectable in the sera of tumor-bearing mice and cancer patients. Biochim Biophys Acto 1994; 1221:211-14

157 Tempfer C, Obermair A, Hefler L, et al. Vascular endothelial growth factor serum concentrations in ovarian cancer. Obstet Gynecol 1998;92:360-3

158 Wong Te Fong LF, Siddiqui GK, Rolfe KJ, et al. Angiogenesis in primary epithelial ovarian carcinomas. Br J Obstet Gynaecol 2001;108:555.

159 Nakanishi Y, Kodama J, Tokumo K, et al. The expression of platelet-derived endothelial cell growth factor/thymidine phosphorylase associates with angiogenesis in epithelial ovarian cancer. Int J Clin Oncol 1997; 2:219-23.

160 de Jong JS, van Diest PJ, Baaqk JPA. Heterogeneity and reproducibility of microvessel counts in breast cancer. Lab Invest 1995;73:922-6.

161 Wang JM, Kumar S, Pye D, et al. A monoclonal antibody detects heterogeneity in vascular endothelium of tumours and normal tissue. Int J Cancer 1993;54:363-70.

162 Schlingemann RO, Rietveld FJ, Kwaspen F, et al. Differential expression of markers for endothelial cells, pericytes, and basal lamina in the microvasculature of tumours and granulation tissue. Am J Pathol 1991:138:1335-47

163 Gassparini G, Bonoldi E, Viale G, et al. Prognostic and predictive value of tumour angiogenesis in ovarian carcinoma. Int J Cancer 1966;69:205-11.

164 Nakanishi Y, Kodama J, Yoshinouchi M, et al. The expression of vascular endothelial growth factor and transforming growth factor-beta associates with angiogenesis in epithelian ovarian cancer. Int J Gynecol Pathol 1997; 16:256-2

165 Hollingsworth HC, Kohn EC, Sterinberg SM, et al. Tumor angiogenesis in advanced stage ovarian carcinoma. Am J Pathol 1995;147:33-41.

166 Abulafia O, Ruizi JE, Holcomb K, et al. Angiogenesis in early-invasive low-malignant-potential epithelian ovarian carcinoma. Obstet Gynecol 2000;95:548-52.

167 Weidner N. Intratumour microvessel density as a prognostic factor in cancer [comment]. Am J Pathol 1995;147:9-19.

168 Sheid B. Angiogenic effect of macrophages isolated from ascitic fluid aspirated from women with advanced ovarian cancer. Cancer Lett 1992;62:153-8.

169 Orre M, Rogers PAW. VEGF, VEGFR-1, VEGFR-2, microvessel density and endothelial cell proliferation in tumours of the ovary. Int J Cancer 1999;84:101-8.

170 Weidner N, Sempel JP, Welch WR, et al. Tumour angiogenesis and metastasis correlation in invasive breast carcinoma. N Engl J Med 1991;324:1-8.

171 Weidner N, Carroll PR, Flax J, et al. Tumor angiogenesis correlates with metastasis in invasive prostate carcinoma. Am J Pathol 1993; 143:401-9.

172 Macchiarini P, Fontanini G, Hardin M, et al. Relation of neovascularization to metastasis of non-small-cell lung cancer. Lancet 1992;340:145-6.

173 Tanigawa N, Amaya H, Matsumura M, et al. Extent of tumor vascularization correlates with prognosis and hematogenous metastasis in gastric carcinomas. Cancer Res 1966;56:2671-6.

174 Takebayashi Y, Aklyama S, Yamada K, et al. Angiogenesis as an unfavorable prognostic factor in human colorectal carcinoma. Cancer 1966;78:226-31.

175 Tanigawa N, Amaya H, Matsumura M, et al. Tumor angiogenesis and mode of metastasis in patients with colorectal cancer. Cancer Res 1997;57:1043-6.

176 van Diest PJ, Zevering PJ, Zevering $L C$, et al. Prognostic value of microvessel quantitation in cisplatin treated FIGO 3 and 4 ovarian cancer patients. Pathol Res Pract 1995;191:25-30.

177 Alvarez AA, Krigman HR, Whittaker RS, et al. The prognostic significance of angiogenesis in epithelian ovarian cancer. Clin Cancer Res 1999:5:587-91.

178 Nakayama K, Kanzaki A, Takebayashi Y, et al. Different features of angiogenesis between ovarian and breast carcinoma. Cancer Lett 2001;170:161-7

179 Ogawa S, Kaku T, Kobayashi H, et al. Prognostic significance of microvessel density, vascular cuffing and vascular endothelial growth factor expression in ovarian carcinoma: a special review for clear cell adenocarcinoma. Cancer Lett 2002;176:111-18.

180 Schoell WM, Pieber D, Riech O, et al. Tumor angiogenesis as a prognostic factor in ovarian carcinoma: quantification of endothelia immunoreactivity by image analysis. Cancer 1997:80:2257-62.

181 Emoto $M$, Iwasaki $H$, Mimura K, et al. Differences in the angiogenesis of benign and malignant ovarian tumors, demonstrated by analyses of color Doppler ultrasound, immunohistochemistry, and microvessel density. Cancer 1997;80:899-907.

182 Heimburg S, Oehler MK, Papadopoulos T, et al. Prognostic relevance of the endothelial marker CD 34 in ovarian cancer. Anticancer Res 1999; 19:2527-2529.

183 Hata K, Fujiwaki R, MaedeY, et al. Expression of thymidine phosphorylase in epithelial ovarian cancer: correlation with angiogenesis, apoptosis, and ultrasound-derived peak systolic velocity. Gynecol Oncol 2000;77:26-34.

184 Shimaoka S, Matsushita S, Nitanda T, et al. The role of thymidine phosphorylase expression in the invasiveness of gastric carcinoma. Cancer 2000;88:2220-7.

\section{$\mathrm{ECHO}$}

\section{Gut cancers differentiate without CDX2}

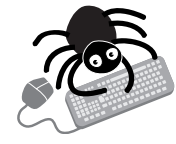

Please visit the Molecular Pathology website [www. molpath.com] for link to this full article.
Cll differentiation in intestinal adenomas and carcinomas has been shown to be regulated independently of a transcription factor important in maintaining gut epithelium. A molecular study has shown a new in vitro model of premalignant adenoma cell lines to be suitable for understanding CDX expression and tumour development and has refuted a previous suggestion that transcription factor CDX2 plays a part in differentiation.

CDX1 and CDX2 were expressed more in the adenoma cell lines compared with two carcinoma cell lines. When the cells were induced to stop growing and instead differentiate by treatment with sodium butyrate, a natural product of the intestinal microflora, expression of CDX1 and CDX2 were unaffected in two selected adenoma cell lines but rose slightly in the carcinoma cell lines. Inducing differentiation by allowing the cell lines to grow to confluence, before assaying for CDX1 and CDX2, gave similar results. However, the level of expression attained fell far short of expression in the adenoma cell lines

CDX1 and CDX2 were assayed by western blotting in six premalignant adenoma cell lines with high expression of these transcription factors and two carcinoma cell lines with lower CDX expression.

CDX1 and CDX2 transcription factors, specified by $C d x$ genes, are reduced in the development of colorectal cancers. CDX2, at least, is important in transcribing genes for differentiation in intestinal epithelium. Existing evidence is based on in vitro studies with cell lines from colorectal cancers whereas this new evidence comes from adenoma cell lines, which are closer to "normal" colonic epithelium.

( Gut 2002;51:184-190. 